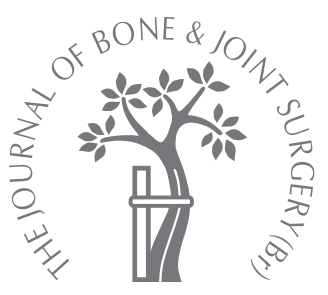

T. Nakajima, S. Ohtori, G. Inoue, T. Koshi, S. Yamamoto, J. Nakamura, K. Takahashi, Y. Harada

From Chiba University, Chiba, Japan

\title{
The characteristics of dorsal-root ganglia and sensory innervation of the hip in rats
}

\author{
Using a rat model the characteristics of the sensory neurones of the dorsal-root ganglia \\ (DRG) innervating the hip were investigated by retrograde neurotransport and \\ immunohistochemistry. \\ Fluoro-Gold solution (FG) was injected into the left hip of ten rats. Seven days later the \\ DRG from both sides between T12 and L6 were harvested. The number of FG-labelled \\ calcitonin gene-related peptide-immunoreactive or isolectin B4-binding neurones were \\ counted. \\ The FG-labelled neurones were distributed throughout the left DRGs between T13 and \\ L5, primarily at L2, L3, and L4. Few FG-labelled isolectin B4-binding neurones were present \\ in the DRGs of either side between T13 and L5, but calcitonin gene-related peptide- \\ immunoreactive neurones made up $30 \%$ of all FG-labelled neurones. \\ Our findings may explain the referral of pain from the hip to the thigh or lower leg \\ corresponding to the L2, L3 and L4 levels. Since most neurones are calcitonin gene-related \\ peptide-immunoreactive peptide-containing neurones, they may have a more significant \\ role in the perception of pain in the hip as peptidergic DRG neurones.
}

Pain arising from the hip has been described classically as presenting in the groin with referral to the anterior thigh and knee. In osteoarthritis $(\mathrm{OA})$, avascular necrosis $(\mathrm{AVN})$ and fracture of the hip, pain has been reported to affect the thigh or lower leg as well as the area of the hip itself. It can be difficult to distinguish between pain referred from the hip and radicular pain originating from a lumbar lesion.

The precise pattern of the sensory innervation of the hip is not known. A recent study on OA of the hip found that referred pain was localised to the groin $(85 \%)$, buttock $(36 \%)$, greater trochanter $(15 \%)$, anterior thigh $(16 \%)$, knee $(12 \%)$ and lower back $(11 \%)$, which correspond to the L1 to L5 dermatomes. ${ }^{1,2}$

Anatomical study has revealed that the femoral, sciatic and superior gluteal nerves innervate the capsule of the hip. ${ }^{3}$ However, the precise segmental distribution of the dorsalroot ganglia (DRG), which innervate the hip has not been clarified.

The neurones of the DRG can be divided into three categories: large neurones, and small neurones which either contain or do not contain neuropeptides. ${ }^{4}$ The former have a proprioceptive function ${ }^{5}$ whereas the latter are sensory and are involved in the perception of pain. The small neurones can be divided into three categories. The first typically includes small, peptide-containing neurones which are immunoreactive (IR) for substance P (SP) and calcitonin gene-related peptide (CGRP). ${ }^{5,6}$ The second group consists of small, non-peptidecontaining neurones which bind the isolectin B4 (IB4) from Griffonia simplicifolia. ${ }^{5,7}$ In the third category are neurones which contain the ratelimiting enzyme tyrosine hydroxylase involved in catecholamine synthesis. This is found in $10 \%$ to $15 \%$ of all DRG neurones. Those neurones are neither 'peptidergic' nor 'non-peptidergic' as shown by a low degree of co-existence with both CGRP and IB4 binding. ${ }^{8}$

Currently, four different states of pain are recognised. Nociceptive pain arises in response to acute injury and reflects the activation of specialised pain receptors. Inflammatory pain occurs in response to tissue injury and is the most common type of pain associated with musculoskeletal disease. Neuropathic pain occurs in the presence of nerve injury. Idiopathic pain has an aetiology which remains unexplained. Under this classification, arthritic pain, including referred pain and tenderness felt remotely from the site of joint pathology, most closely corresponds to an inflammatory state. $^{9}$ 


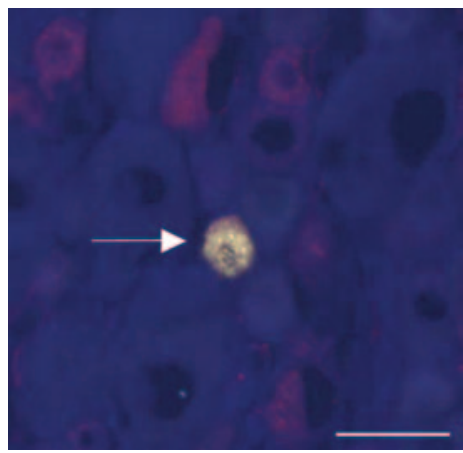

Fig. 1a

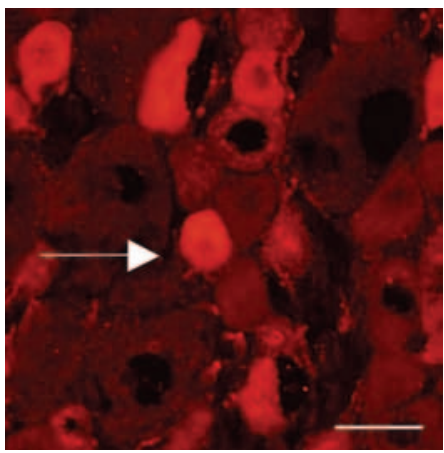

Fig. 1b

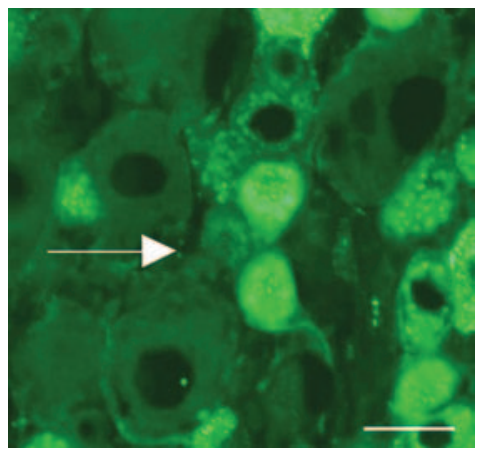

Fig. 1c

Fluorescent photomicrographs of the left L4 (dorsal root ganglia) after injection of Fluoro-Gold solution into the hip showing a) Fluoro-Gold solution-labelled b) CGRP-IR (c) and IB4 binding b) dorsal root ganglia neurones. The arrows show a Fluoro-Gold solution-labelled neurone innervating the hip. The CGRP-IR neurones are labelled red and IB4-binding neurones green. The Fluoro-Gold solution-labelled neuron is CGRP-IR (a and b) and non-IB4-binding (a and c) (scalebars are $50 \mu \mathrm{m}$ in a).

Our aim was to determine the distribution of DRG neurones innervating the hip and the proportion of IB4-binding and CGRP-labelled DRG involved in the rat using retrograde neurotransport, lectin affinity and immunohistochemistry.

\section{Materials and Methods}

We used ten male Sprague-Dawley rats weighing $250 \mathrm{~g}$ to $300 \mathrm{~g}$. The protocols for the animal procedures in these experiments followed the 1996 revision of the National Institutes of Health guidelines for the Care and Use of Laboratory Animals (available from Chiba University) and received approval from the ethics committee of Chiba University. The rats were anaesthetised by an intraperitoneal injection of sodium pentobarbital $(40 \mathrm{mg} / \mathrm{kg})$ and treated aseptically throughout the experiments. Using a 26-gauge needle, $30 \mu \mathrm{l}$ of $1 \%$ Fluoro-Gold solution (FG); (Fluorochrome, Denver, Colorado) was injected into the left hip of each rat.

Seven days later, the rats were anaesthetised with sodium pentobarbital (40 mg/kg, intraperitoneally) and perfused transcardially with $0.9 \%$ saline, followed by $500 \mathrm{ml}$ of $4 \%$ paraformaldehyde in phosphate buffer $(0.1 \mathrm{M}, \mathrm{pH} 7.4)$. The DRGs between T12 and L6 on both sides were resected. The specimens were immersed in the same fixative solution overnight at $4^{\circ} \mathrm{C}$. After storage in $0.01 \mathrm{M}$ phosphate-buffered saline (PBS) containing 20\% sucrose for 20 hours at $4^{\circ} \mathrm{C}$, each DRG was sectioned at a thickness of $10 \mu \mathrm{m}$ on a cryostat and mounted on poly-l-lysine-coated slides.

Isolectin B4-binding and Calcitonin gene-related peptide immunohistochemistry. Endogenous tissue peroxidase activity was quenched by soaking the sections for $30 \mathrm{~min}-$ utes in $0.3 \%$ hydrogen peroxide solution in $0.01 \mathrm{M}$ PBS. The specimens were then treated in a blocking solution, 0.01 M PBS containing $0.3 \%$ Triton X-100 and 3\% skimmed milk, overnight at $4^{\circ} \mathrm{C}$. They were processed for
IB4-binding and CGRP immunohistochemistry using biotin-labelled IB4 (1:1000; Chemicon, Temecula, California) and rabbit antibody to CGRP (1:1000; Chemicon), diluted with a blocking solution, and incubated overnight at $4^{\circ} \mathrm{C}$. After incubation with labelled isolectin or antibody, the sections were incubated with goat antirabbit Alexa 594 (Texas red fluorescent dye) for CGRPimmunoreactivity (1:1000; Molecular Probes Inc, Eugene, Oregon) or streptavidin Alexa 488 fluorescent antibody conjugate for IB4-binding (1:1000; Molecular Probes Inc).

After each step, the sections were rinsed in 0.01 M PBS three times and studied using fluorescence microscopy. The number of FG-labelled neurones and those with FG-labelling and IB4-binding or CGRP-IR were counted.

Statistical analysis. Differences in the number of FGlabelled DRG neurones in the DRGs between T12 and L6 were evaluated using the multiple-comparison TukeyKramer test. The proportions of FG-labelled and IB4-binding and CGRP-IR neurones in the DRGs between T12 and L6 were compared using the Mann-Whitney U test. A p-value $<0.05$ was considered to be statistically significant.

\section{Results}

Fluoro-Gold solution-labelled dorsal-root ganglia neurones. Neurones with FG-labelling, in which FG was transported from the hip, were present in the left DRGs between T13 and L5 (Fig. 1a). We found a total of 212 FG-labelled neurones in the ten rats examined, with a minimum of six and maximum of 50 within a rat. No labelled neurones were observed at T12 and L6 in the left DRGs or in the contralateral DRGs between T12 and L6. The largest number of labelled neurones was found in the L4 DRG, and the number of FG-labelled neurones in the L1, L2, L3 and L4 DRGs was significantly higher than that in T13 and L5 (TukeyKramer test, $\mathrm{p}<0.05$; Fig. 2). 


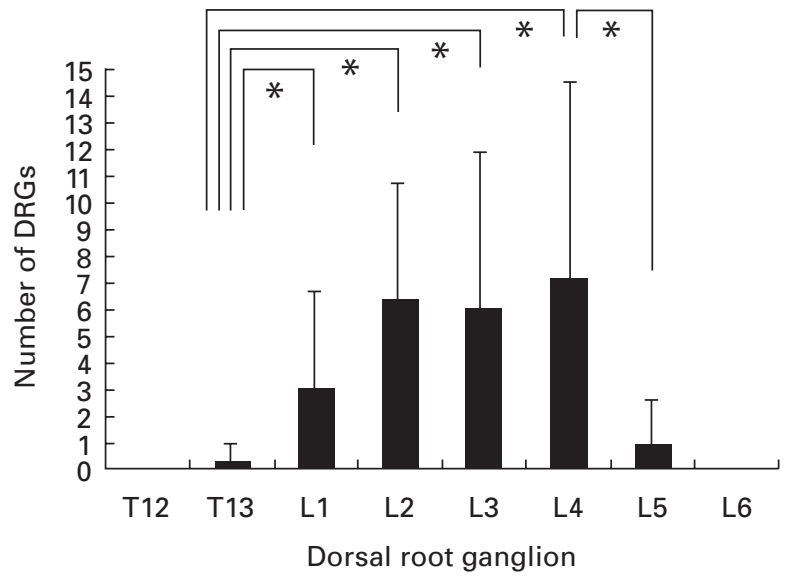

Fig. 2

Bar chart showing the distribution of the mean number of Fluoro-Gold solution-labelled dorsal root ganglia (DRG) neurones innervating the hip. The number of Fluoro-Gold solution-labelled dorsal root ganglia neurones at $L 1, L 2, L 3$ and $L 4$ was significantly higher than that at $T 13$ and L5 (Tukey-Kramer test, $\mathrm{p}<0.05$ ). Error bars represent the SEM $\left({ }^{*} \mathrm{p}<0.05\right)$.

Fluoro-Gold solution-labelled calcitonin gene-related peptide-immunoreactive and Isolectin B4-binding neurones.

The FG-labelled CGRP-IR neurones were present in the left DRGs between L1 and L5 (Fig. 1b) but there were few FGlabelled IB4-binding neurones in the left DRGs between L2 and L4 (Fig. 1c). Of the FG-labelled neurones, the mean percentage of CGRP-IR neurones in DRGs was 18.9 (SEM 32.8) in L1, 29.6 (SEM 36.6) in L2, 35.6 (SEM 18.8) in L3, 50.1 (SEM 29.9) in L4, and 26.7 (SEM 46.2) in L5. The mean percentage of IB4-binding neurones was 0.9 (SEM 2.8) in L2, 2.1 (SEM 4.8) in L3 and 1.9 (SEM 5.0) in L4. The mean percentage of CGRP-IR neurones was significantly higher than that of IB4-binding neurones at each level between L2 and L4 (Mann-Whitney U test, $\mathrm{p}<0.05$; Fig. 3).

\section{Discussion}

The sensory innervation of the capsule of the human hip has been studied anatomically. It has been reported that the anteromedial area is innervated by the articular branch of the obturator nerve and the anterior portion by the articular branch of the femoral nerve. ${ }^{3}$ In other words, these areas are reportedly innervated from nerves derived from levels L2 to L4. Additionally, the posterior area of the capsule is innervated by the articular branch of the sciatic nerve and the posteromedial area by the superior gluteal nerve, both of which are derived from levels L4 to S1.

The thoracic spinal cord in the rat is divided into 13 and the lumbar spinal cord into six segments. Although the segmentation differs between the spinal cord of the human and the rat, the form of segmentation and the structure of the spinal cord are similar in both species.

In our study, the hip was innervated between the ipsilateral T13 and L5 DRG. Most of the DRG neurones inner-

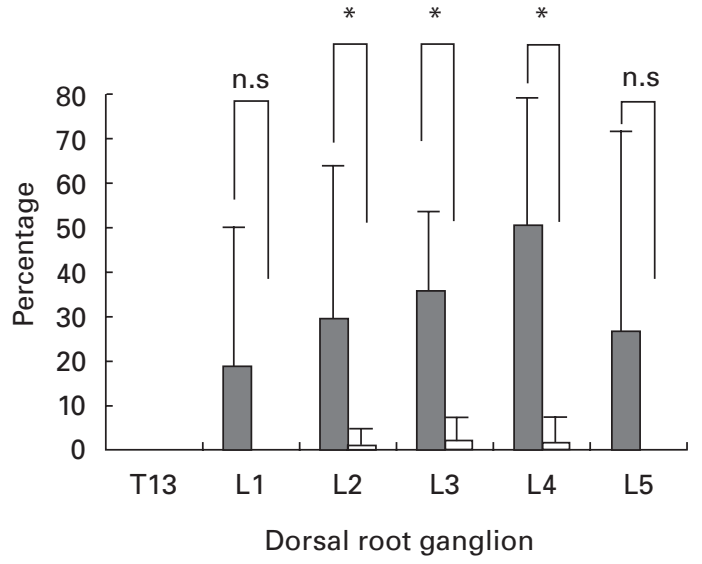

Fig. 3

Bar chart showing the mean percentage of Fluoro-Gold solution-labelled CGRP-IR dorsal root ganglia neurones and IB4-binding at each level. The percentage of CGRP-IR neurones from L2 to L4 was significantly higher than that of IB4-binding neurones at each level (Mann-Whitney $U$ test, $\mathrm{p}<0.05)$. Error bars represent the SEM (sc) $(*, p<0.05)$. ns, not significant.

vating the rat hip were distributed in L1, L2, L3 and L4. Our results support the findings from human anatomical studies and may explain the clinical observation of pain referred to the thigh and lower leg in patients with disorders of the hip.

Another recent theory of referred pain suggests that increased tenderness over apparently normal tissues may indicate that changes which occur in the central modulation of nociceptive input may contribute to the symptoms of OA. ${ }^{10}$

Neural mechanisms of referred pain have not yet been clarified, although two hypotheses have been proposed. First, the convergence-projection hypothesis proposed by Ruch $^{11}$ suggests that somatic and visceral fibres from each of the primary neurones converge upon one dorsal horn neurone in the spinal cord. Several experimental studies have supported this hypothesis. ${ }^{11-13}$ Secondly, the concept of referred pain of Sinclair, Weddell and Feindel ${ }^{14}$ suggests that there are primary afferent fibres bifurcating into somatic and visceral structures.

There was, however, a limitation to our study. The FG solution was distributed throughout the entire hip including the capsule, synovium, bone and cartilage. Therefore the sensory innervation of specific tissue within the hip could not be identified, and there may be different patterns of sensory innervation for each tissue. Further experimentation is needed for clarification.

Two major classes of $\mathrm{C}$ fibres in small DRGs have recently been recognised. Most small DRG neurones are thought to transmit nociceptive information. Small DRG neurones are subclassified into nerve-growth-factor (NGF)-dependent neurones $(40 \%$ of total DRG neurones), ${ }^{6,7,15,16}$ which express a high-affinity NGF-receptor 
tyrosine kinase $\mathrm{A}, 6,7$ and glial-cell-line-derived-neurotrophic-factor (GDNF)-dependent neurones $(32 \%$ of total DRG neurones), ${ }^{17,18}$ which express the GDNF receptor. ${ }^{17,19}$ The NGF-dependent neurones contain neuropeptides such as SP and CGRP, ${ }^{5}$ whereas GDNF-dependent neurones lack neuropeptides but bind IB4. Therefore, these two types of small DRG neurones can be distinguished by immunoreactivity for CGRP and binding of IB4.

In our study, neurones innervating the hip were colabelled with FG and CGRP. One-third of FG-labelled neurones were CGRP-IR, but IB4 binding was observed in a small number of FG-labelled neurones.

Nociceptive information is normally transmitted by small DRG neurones to the dorsal horn of the spinal cord. These small neurones may be subclassified into two groups. One, comprising peptide-containing neurones, contains CGRP. ${ }^{5-7}$ These terminate in lamina I and the outer layer of lamina II in the dorsal horn of the spinal cord. ${ }^{7}$ The other group, comprising non-peptide-containing neurones, expresses the IB4-binding glycoprotein. ${ }^{5}$ The DRG neurones co-labelled with IB4 terminate at the inner part of lamina II in the dorsal horn of the spinal cord. ${ }^{7,20}$ The peptidergic subpopulation is considered to be particularly important in inflammatory conditions, whereas the IB4binding subpopulation is involved in neuropathic states. ${ }^{5} \mathrm{In}$ addition, IB4-binding neurones have also been implicated in the nociception of acute pain. When IB4-binding neurones are selectively destroyed with toxin, animals show behavioural signs of decreased sensitivity to acute pain. ${ }^{21}$

The IB4-binding neurones may mediate several states of pain, such as acute or chronic, which originate from nerve injury. On the basis of previous reports ${ }^{5-7}$ and our study, CGRP-IR neurones may have a significant role in the appreciation of pain in the hip through peptidergic DRG neurones related to inflammatory pain.

It has been found that the proportion of IB4-binding neurones innervating skin $(43 \%)$ is higher than that innervating the bladder $(29 \%){ }^{15}$ Muscle afferent neurones showed 22\% CGRP-IR and 5\% IB4-binding. On the other hand, cutaneous afferent neurones had 26\% CGRP-IR and $44 \%$ IB4-binding. ${ }^{22}$ The proportions of IB4-binding and SP-IR DRG neurones innervating the rat lumbar disc were $0.6 \%$ and $44 \%$, respectively. ${ }^{23}$ It has been reported that IB4-binding neurones are not present in the rat knee. ${ }^{24}$ Based on these studies and our findings, it seems likely that organs located in deep layers of the body, such as joints and the spinal structures, are innervated by fewer IB4-binding DRG neurones.

Pain from the hip may be mainly transmitted by CGRP-IR DRG neurones. Clinically, it is difficult to distinguish referred pain from the hip and pain from other sources. Therefore, it is important to consider the mechanism of pain in disorders of the hip.

No benefits in any form have been received or will be received from a commercial party related directly or indirectly to the subject of this article.

\section{References}

1. Khan NO, Woolson ST. Referral patterns of hip pain in patients undergoing total hip replacement. Orthopedics 1998;21:123-6.

2. Nakamura J, Oinuma K, Suzuki C, et al. Frequency distribution of pain in osteoarthritis of the hip. Rinshoseikeigeka 2006;41:991-4 (in Japanese).

3. Birnbaum K, Prescher A, Hepler S, Heller D. The sensory innervation of the hip: an anatomical study. Surg Radiol Anat 1997;19:371-5.

4. Takahashi Y, Chiba T, Kurokawa M, et al. Stereoscopic structure of sensory nerve fibres in the lumbar spine and related tissues. Spine 2003;28:871-80.

5. Snider WD, McMahon SB. Tackling pain at the source: new ideas about nociceptors. Neuron 1998;20:629-32.

6. Averill S, McMahon SB, Clary DO, Reichardt LF, Priestley JV. Immunocytochemical localization of trkA receptors in chemically identified subgroups of adult rat sensory neurons. Eur J Neurosci 1995; 7:1484-94

7. Molliver DC, Radeke MJ, Feinstein SC, Snider WD. Presence or absence of TrkA protein distinguishes subsets of small sensory neurons with unique cytochemical characteristics and dorsal horn projections. J Comp Neuro/ 1995;361:404-16.

8. Brumovsky P, Villar MJ, Hökfelt T. Tyrosine hydroxylase is expressed in a subpopulation of small dorsal root ganglion neurons in the adult mouse. Exp Neuro/2006;200:153-65.

9. Kidd BL, Langford RM, Wodehouse T. Arthritis and pain: current approaches in the treatment of arthritic pain. Arthritis Res Ther 2007;11:214

10. Kidd BL. Osteoarthritis and joint pain. Pain 2006;123:6-9.

11. Ruch TC. Visceral sensation and referred pain. In: Fulton JF, ed. Howell's textbook of physiology. Fifteenth ed. Philadelphia: WB Saunders, 1946:385-401.

12. Rucker HK, Holloway JA. Viscerosomatic convergence onto spinothalamic tract neurons in the cat. Brain Res 1982;243:155-7.

13. Selzer M, Spencer WA. Convergence of visceral and cutaneous afferent pathways in the lumbar spinal cord. Brain Res 1969;14:331-48.

14. Sinclair DC, Weddell G, Feindel WH. Referred pain and associated pheomena. Brain 1948;71:184-211.

15. Bennett DLH, Dmietrieva N, Priestley JV, Clary D, McMahon SB. TrkA, CGRP and IB4 expression in retrogradely labelled cutaneous and visceral primary sensory neurons in the rat. Neurosci Lett 1996;206:33-6.

16. Verge VM, Merlio JP, Grondin J, et al. Colocalization of NGF binding sites, trk mRNA, and low-affinity NGF receptor mRNA in primary sensory neurons: responses to injury and infusion of NGF. J Neurosci 1992;12:4011-22.

17. Silverman JD, Kruger L. Selective neuronal glycoconjugate expression in sensory and autonomic ganglia: relation of lectin reactivity to peptide and enzyme markers. J Neurocytol 1990;19:789-801.

18. Wang H, Rivero-Melián C, Robertson B, Grant G. Transganglionic transport and binding of the isolectin B4 from Griffonia Simplicifolia I in rat primary sensory neurons. Neuroscience 1994;62:539-51.

19. Bennett DL, Michael GJ, Ramachandran N, et al. A distinct subgroup of small DRG cells express GDNF receptor components and GDNF is protective for these neurons after nerve injury. J Neurosci 1998;18:3059-72.

20. Bradbury EJ, Burnstock G, McMahon SB. The expression of $P 2 X 3$ purinoreceptors in sensory neurons: effects of axotomy and glial-derived neurotrophic factor. $\mathrm{Mol}$ Cell Neurosci 1998;12:256-68.

21. Vulchanova L, Olson TH, Stone LS, et al. Cytotoxic targeting of isolectin IB4-binding sensory neurons. Neurosci 2001;108:143-55.

22. Ambalavanar R, Moritani M, Haines A, Hilton T, Dessem D. Chemical phenotypes of muscle and cutaneous afferent neurons in the rat trigeminal ganglion. J Comp Neurol 2003;460:167-79.

23. Ozawa T, Aoki Y, Ohtori S, et al. The dorsal portion of the lumbar intervertebral disc is innervated primarily by small peptide-containing dorsal root ganglion neurons in rats. Neurosci Lett2003;344:65-7

24. Ivanavicius SP, Blake DR, Chessell IP, Mapp PI. Isolectin B4 binding neurons are not present in the rat knee joint. Neuroscience 2004;128:555-60. 